\title{
Use of the dried blood spot sampling process coupled with fast gas chromatography and negative-ion chemical ionization tandem mass spectrometry: application to fluoxetine, norfluoxetine, reboxetine, and paroxetine analysis
}

\author{
Julien Déglon • Estelle Lauer • Aurélien Thomas • \\ Patrice Mangin $\cdot$ Christian Staub
}

Received: 21 September 2009/Revised: 14 December 2009/Accepted: 15 December 2009/Published online: 10 January 2010

(C) Springer-Verlag 2010

\begin{abstract}
The objective of this work was to combine the advantages of the dried blood spot (DBS) sampling process with the highly sensitive and selective negative-ion chemical ionization tandem mass spectrometry (NICI-MS-MS) to analyze for recent antidepressants including fluoxetine, norfluoxetine, reboxetine, and paroxetine from micro whole blood samples (i.e., $10 \mu \mathrm{L}$ ). Before analysis, DBS samples were punched out, and antidepressants were simultaneously extracted and derivatized in a single step by use of pentafluoropropionic acid anhydride and $0.02 \%$ triethylamine in butyl chloride for $30 \mathrm{~min}$ at $60{ }^{\circ} \mathrm{C}$ under ultrasonication. Derivatives were then separated on a gas chromatograph coupled with a triple-quadrupole mass spectrometer operating in negative selected reaction monitoring mode for a total run time of $5 \mathrm{~min}$. To establish the validity of the method, trueness, precision, and selectivity were determined on the basis of the guidelines of the "Société Française des Sciences et des Techniques Pharmaceutiques" (SFSTP). The assay was found to be linear in the concentration ranges 1 to $500 \mathrm{ng} \mathrm{mL}^{-1}$ for fluoxetine and norfluoxetine and 20 to $500 \mathrm{ng} \mathrm{mL}^{-1}$ for reboxetine and paroxetine. Despite the small sampling
\end{abstract}

\footnotetext{
J. Déglon $\cdot$ E. Lauer $\cdot$ A. Thomas $\cdot$ P. Mangin $\cdot$ C. Staub $(\bowtie)$

Unit of Toxicology, University Center of Legal Medicine,

1 rue Michel-Servet,

1211 Geneva 4, Switzerland

e-mail: Christian.staub@hcuge.ch

J. Déglon $\cdot$ E. Lauer $\cdot$ A. Thomas $\cdot$ C. Staub

Swiss Center of Applied Human Toxicology,

University of Geneva,

35 rue des Bains,

1205 Geneva, Switzerland
}

volume, the limit of detection was estimated at $20 \mathrm{pg} \mathrm{mL}^{-1}$ for all the analytes. The stability of DBS was also evaluated at $-20{ }^{\circ} \mathrm{C}, 4{ }^{\circ} \mathrm{C}, 25{ }^{\circ} \mathrm{C}$, and $40{ }^{\circ} \mathrm{C}$ for up to 30 days. Furthermore, the method was successfully applied to a pharmacokinetic investigation performed on a healthy volunteer after oral administration of a single 40-mg dose of fluoxetine. Thus, this validated DBS method combines an extractive - derivative single step with a fast and sensitive GC-NICI-MS-MS technique. Using microliter blood samples, this procedure offers a patient-friendly tool in many biomedical fields such as checking treatment adherence, therapeutic drug monitoring, toxicological analyses, or pharmacokinetic studies.

Keywords DBS · Fast GC · NICI-MS-MS .

Antidepressants $\cdot$ Pharmacokinetics

\section{Introduction}

Until 1980, the first line of depression treatment was tricyclic antidepressants and monoamine oxidase inhibitors. Their pharmacological action was attributed to increasing the synaptic concentration of the noradrenergic and serotonergic neurotransmitters. However, these compounds present many side effects due to binding to multiple receptors, cardiotoxicity and diverse drug-drug interactions that may lead to severe intoxication $[1,2]$.

In 1980, an important new class of antidepressants was introduced, the selective serotonin reuptake inhibitors (SSRIs), including fluoxetine and paroxetine. This class has become a mainstay of antidepressant treatment due to 
its better safety and tolerability [1]. More recently, newer antidepressants have been developed, including noradrenergic reuptake inhibitors (NaRIs) such as reboxetine.

However, even if these new compounds have fewer undesirable effects, they are frequently used in deliberate self-poisoning and can lead to major intoxication [3-5]. Furthermore, some depressed patients do not respond to their treatment, because of non-compliance or co-medication with inducers of their enzymes $[6,7]$. Thus, analysis of antidepressants is required in many fields such as therapeutic drug monitoring or forensic toxicology.

Traditionally, clinical and/or toxicological analyses are performed using plasma obtained by venipuncture [8, 9]; however, this sampling form requires a hospital infrastructure and can be hazardous for the patient population where venous collection is problematic [10]. Among alternative sampling procedures, use of filter paper as a support for blood collection seems to be a powerful and patient-friendly tool.

Referred to as dried blood spot (DBS), this alternative procedure was successfully introduced by Guthrie et al. in 1963 for collecting newborns' capillary blood for the neonatal screening of phenylketonurea. Since then, the filter paper $903 \mathrm{~S} \& \mathrm{~S}$ produced by Whatman has been introduced for multiple neonatal metabolic disorder screening programs worldwide [11].

The DBS procedure offers the advantages, compared with venipuncture, of being less invasive and more costeffective in terms of sample collection, shipment, and storage [12, 13]. Indeed, blood samples are collected from a small finger prick with an automatic lancet, enabling nonhospital based sampling, so that patients can even perform the sampling themselves at home $[14,15]$. Furthermore, the DBS sampling process does not require the use of anticoagulant or plasma separation and ensures better stability of the compounds during shipment and storage without using a refrigeration device [16-18]. Security is also improved by the deactivation of potential pathogens, for example HIV virus, on the filter paper [15, 19, 20].

Because of these advantages, DBS was recently applied to the monitoring of therapeutic agents including antimalarials, antiepileptics, antiretrovirals, antidiabetics, and antibiotics $[8,21-27]$.

An important analytical aspect to take in consideration with the DBS procedure is the limited sample volume, which may be problematic in terms of sensitivity, especially at lower therapeutic concentration levels. This lack has to be compensated by the use of highly sensitive detectors such as triple-stage mass spectrometers operating in the selected reaction monitoring (SRM) mode [28]. Although the use of tandem mass spectrometry (MS-MS) with atmospheric-pressure ionization (API) coupled to liquid chromatography is known to be the gold standard for quantification of pharmaceutical compounds [29, 30], negative-ion chemical ionisation (NICI) combined with gas chromatography (GC) is an interesting alternative. Indeed, NICI has been demonstrated to be a very highly sensitive and selective ionization mode [31-33], and has been successfully applied to different classes of pharmaceutical compounds, for example antidepressants, benzodiazepines, opioids, and cannabinoids [34-39].

Nevertheless, NICI generally requires a derivatization step to improve the electro-affinity of the analytes. This step is often tedious and time-consuming. An important part of this work was focused on optimization of the derivatization step to decrease the sample preparation time. Thus, derivatization of the antidepressants was combined in a single step with extraction of the DBS.

This article describes a new efficient method for quantitative monitoring of three antidepressants and one phase I metabolite in whole blood by combining the DBS sampling procedure with accelerated GC separation coupled to NICI-MS-MS detection. Because of its high sensitivity and selectivity, this approach is particularly interesting for clinical and toxicological analyses because only $10 \mu \mathrm{L}$ blood is required.

\section{Experimental}

\section{Chemicals and reagents}

Fluoxetine, fluoxetine $\mathrm{d}_{6}$, norfluoxetine, and norfluoxetine $\mathrm{d}_{6}$ at $1000 \mu \mathrm{g} \mathrm{mL}^{-1}$ or $100 \mu \mathrm{g} \mathrm{mL}^{-1}$ in methanol were purchased from Cambridge Isotope Laboratory (Andover, USA). Reboxetine, paroxetine, and paroxetine $d_{6}$ were purchased from Sigma-Aldrich (Steinheim, Germany). Reboxetine $d_{5}$ was obtained from Toronto Research Chemicals (North York, Canada).

Working standard solutions were prepared by dilution of stock solutions with methanol to reach concentrations of interest ranging from 1 to $10 \mu \mathrm{g} \mathrm{mL} \mathrm{mL}^{-1}$, except for deuterated compounds, used as internal standards (IS), which were prepared in a vial by dilution with methanol to reach concentrations of $250 \mathrm{ng} \mathrm{mL}^{-1}$ for fluoxetine $\mathrm{d}_{6}$ and norfluoxetine $d_{6}$ and $500 \mathrm{ng} \mathrm{mL}^{-1}$ for both reboxetine $d_{5}$ and paroxetine $\mathrm{d}_{6}$. After use, stock and working solutions were stored at $-20{ }^{\circ} \mathrm{C}$.

Pentafluoropropionic anhydride (PFPA) 99\% and triethylamine $99 \%$ were obtained from Sigma-Aldrich (Bellefonte, USA). All solvents used, for example hexane, methanol, and butyl chloride, were of high-performance chromatographic grade from Merck (Darmstadt, Germany) and Romil (Obergoesgen, Switzerland). Human blood was supplied by the Geneva University Hospitals (Geneva, Switzerland); EDTA was used as anti-coagulant. 
DBS sample processing

\section{Preparation of calibration standards and quality} control samples

Calibration standards (Cal) were prepared one day before analysis. After evaporation of appropriate working standard solutions previously added to Eppendorf tubes, antidepressantfree EDTA - whole blood was added to reach a calibration range of 1 to $500 \mathrm{ng} \mathrm{mL}^{-1}$ for both fluoxetine and norfluoxetine and 20 to $500 \mathrm{ng} \mathrm{mL}^{-1}$ for both paroxetine and reboxetine.

Quality controls (QC) were simultaneously and independently prepared in the same way in our laboratory. Four QC samples at concentrations of 1,20,250, and $500 \mathrm{ng} \mathrm{mL}-1$ for both fluoxetine and norfluoxetine and 20,40, 250, and $500 \mathrm{ng} \mathrm{mL} \mathrm{m}^{-1}$ for both paroxetine and reboxetine were prepared one day before analysis, similarly to the calibration standards.

\section{Blood spotting}

Real or spiked whole blood $(10 \mu \mathrm{L})$ was spotted on a filter paper card, item no. 105355097 from Whatman, Schleicher and Schuell (Dassel, Germany), using a volumetric micropipette (Eppendorf, Hamburg, Germany). The blood spots were allowed to dry at room temperature for $2 \mathrm{~h}$ and then packed in a sealable plastic bag containing a desiccant pad until analysis. They were stored in the dark at ambient temperature except for short-term stability experiments, in which different temperatures were tested.

\section{DBS sample preparation}

Before analysis, DBS were punched out, and $5 \mu \mathrm{L}$ IS was added directly on to the disc. Extraction and derivatization were performed simultaneously in a single step by adding $500 \mu \mathrm{L} 0.02 \%$ triethylamine in butyl chloride and $100 \mu \mathrm{L}$ PFPA, followed by ultrasonication for $30 \mathrm{~min}$ at $60{ }^{\circ} \mathrm{C}$. The organic phase was then transferred into a conical vial and evaporated to dryness under a stream of nitrogen. Finally, the fluorinated derivatives were reconstituted with $50 \mu \mathrm{L}$ hexane, and $2 \mu \mathrm{L}$ was injected into the GC-MS system.

\section{GC-NICI-MS-MS analysis}

Analyses were performed on a Varian (Walnut Creek, CA, USA) CP 3800 gas chromatograph in combination with a CTC Combi-PAL autosampler (Zwingen, Switzerland) and a Varian 1200 L MS-MS triple-quadrupole mass spectrometer. Data acquisition and analysis were performed using Varian MS Workstation software (6.8).
Chromatographic conditions

Substances were separated using a fused-silica capillary column (DB-5MS, $15 \mathrm{~m} \times 0.25 \mathrm{~mm}$ i.d., film thickness $0.25 \mu \mathrm{m})$, and high-purity helium $(99.999 \%)$ was used as the carrier gas with a constant flow of $1 \mathrm{~mL} \mathrm{~min}{ }^{-1}$. For all of the analyses, the injector temperature was set at $300{ }^{\circ} \mathrm{C}$, and splitless injection was used, with the injection purge valve remaining closed for $1 \mathrm{~min}$.

Under fast GC-MS-MS conditions, the initial column temperature was set at $105^{\circ} \mathrm{C}$ for $1 \mathrm{~min}$, increased to $300^{\circ} \mathrm{C}$ at $70^{\circ} \mathrm{min}^{-1}$, and held for $1.22 \mathrm{~min}$ for a total analysis time of $5 \mathrm{~min}$.

\section{Mass spectrometric detection}

Methane (purity of $99.9995 \%$ ) was used as reagent gas for NICI analyses at a pressure between 8 and 8.5 Torr. Transfer line, manifold, and ion source were operated at 275,40 , and $150{ }^{\circ} \mathrm{C}$, respectively. The mass spectrometer was operated in the negative SRM mode with MS-MS experiments based on collisionally induced dissociation (CID) occurring in the collision cell (quadrupole 2), with an argon collision gas pressure of 1.3 mTorr.

All MS-MS conditions are shown in Table 1. The transitions chosen for each compound were based on criteria of abundance and selectivity. The different NICIMS-MS conditions (reagent gas pressure, CID pressure, collisional energy) were optimized with the use of antidepressant standard solutions (data not presented here). In fast GC mode, the duty cycle was set at $0.15 \mathrm{~s}$ to obtain a sufficient number of work points to meet quantitative needs (between 9 and 12 points).

Validation procedure

A full validation procedure for human dried blood spots was conducted according to the guidelines of the "Société Française des Sciences et des Techniques Pharmaceutiques" (SFSTP) [40].

On each of three non-consecutive days, DBS Cal were prepared in duplicate $(n=2)$ at five concentration levels $\left(k=5 ; \mathrm{Cal}=1,20,50,150\right.$, and $500 \mathrm{ng} \mathrm{mL}^{-1}$ for both fluoxetine and norfluoxetine, and $\mathrm{Cal}=20,50,150,300$, and $500 \mathrm{ng} \mathrm{mL} L^{-1}$ for reboxetine and paroxetine) for determining the response function. Furthermore, DBS QC were prepared independently in the same way in quadruplicate $(n=4)$ at four concentration levels $(k=4 ; \mathrm{QC}=1,20,250$, and $500 \mathrm{ng} \mathrm{mL}^{-1}$ for both fluoxetine and norfluoxetine, and $\mathrm{QC}=$ $20,40,250$, and $500 \mathrm{ng} \mathrm{mL}^{-1}$ for reboxetine and paroxetine), representing the entire range of concentrations.

Validation enabled determination of specific criteria such as trueness, precision, linearity, limit of quantification 
Table 1 MS-MS conditions for antidepressants

\begin{tabular}{lllll}
\hline Antidepressant & Molecular mass compound/derivative $\left(\mathrm{gmol}^{-1}\right)$ & $\mathrm{Q} 1 \rightarrow \mathrm{Q} 3(\mathrm{~m} / \mathrm{z})$ & Collision energy $(\mathrm{eV})$ & Retention time $(\mathrm{min})$ \\
\hline Norfluoxetine d6 & $301 / 447$ & $472 \rightarrow 265$ & 5 & 3.4 \\
Norfluoxetine & $295 / 441$ & $421 \rightarrow 161$ & 15 & 3.4 \\
& & $421 \rightarrow 259$ & 10 & 3.5 \\
Fluoxetine d6 & $315 / 461$ & $441 \rightarrow 161$ & 5 & 3.5 \\
Fluoxetine & $309 / 455$ & $435 \rightarrow 161$ & 5 & 4.1 \\
& & $435 \rightarrow 306$ & 15 & 4.1 \\
Reboxetine d5 & $318 / 464$ & $424 \rightarrow 404$ & 5 & 10 \\
Reboxetine & $313 / 459$ & $419 \rightarrow 109$ & 10 & \\
& & $419 \rightarrow 137$ & 15 & 4.7 \\
Paroxetine d6 & $335 / 481$ & $441 \rightarrow 109$ & 15 & 4.7 \\
Paroxetine & $329 / 475$ & $435 \rightarrow 109$ & 15 & 15
\end{tabular}

(LOQ), and limit of detection (LOD), which will be discussed later.

\section{Recovery and matrix effects}

The efficiency of the procedure was evaluated by comparing the absolute analyte peak area from DBS spiked with all antidepressants at the concentration of $250 \mathrm{ng} \mathrm{mL}^{-1} \mathbf{1}$, with the corresponding methanolic solutions spiked directly into the extraction tube containing $\mathbf{2}$, or not $\mathbf{3}$, antidepressant-free DBS specimen. Recovery and matrix effects were obtained by using the $\mathbf{1} / \mathbf{3}$ and the $\mathbf{2} / \mathbf{3}$ ratios respectively [41]. For each experiment, analyses were performed in triplicate.

\section{Stability of DBS}

To test the short-term stability of the antidepressants on filter paper, three batches of antidepressant-free whole blood were spiked with all the analytes at $250 \mathrm{ng} \mathrm{mL}$. DBS samples were prepared using the same procedure described in the section "Blood spotting" and subsequently stored at different temperatures $\left(-20^{\circ} \mathrm{C}, 4{ }^{\circ} \mathrm{C}, 21{ }^{\circ} \mathrm{C}\right.$, and $\left.40^{\circ} \mathrm{C}\right)$. Stability study was carried out over one month with time points of $1,3,5,15$, and 30 days. For each time point, DBS samples were analyzed in triplicate with a waiting period of $12 \mathrm{~h}$ at ambient temperature before the analysis.

\section{Pharmacokinetic investigation}

The described procedure was applied to the monitoring of fluoxetine and its main phase I metabolite norfluoxetine after oral administration of a single 40-mg dose of fluoxetine (two capsules of $20 \mathrm{mg}$ Fluctine, Eli Lilly, Geneva, Switzerland) to a healthy male volunteer $(68 \mathrm{~kg}, 180 \mathrm{~cm})$.

Capillary whole blood was collected at different time points over one month using the DBS sampling process.
Except for the first day, all DBS samples were performed at home by the volunteer himself after a finger prick made on the top of the finger with a disposable lancet. At each time point, five spots of $10 \mu \mathrm{L}$ of capillary blood were collected and stored on filter paper card using the procedure described in the section "Blood spotting". Last, filter paper cards were sent to our laboratory by mail in a sealable plastic bag containing a desiccant pad.

Because norfluoxetine is known to contribute to the overall therapeutic and/or toxic effect [7, 31, 42, 43], both the parent drug and the active metabolite were quantified from DBS in duplicate for each time point. In addition, pharmacokinetic parameters were estimated for these analytes by a non-compartmental method using WinNonlin version 4.1 (Pharsight, Mountainview, California, USA). Pharmacokinetic parameters such as $C_{\max }, T_{\max }$, and $t_{1 / 2}$ were calculated from standard equations using WinNonlin, and $\mathrm{AUC}_{0-\infty}$ was calculated using the trapezoidal rule.

\section{Results and discussion}

\section{DBS sample preparation}

Use of the DBS sampling process requires an extractive step before analysis. The challenge is to remove the compounds of interest from the filter paper and to retain blood components. Generally, a mixture of water and organic solvents, for example acetonitrile or methanol, is employed [8, 15, 44, 45]. However, protic solvents are unsuitable with the simultaneous use of acylation agents such as fluorinated agents. Therefore, a large part of the method development was focusing on the combination of extraction solvent with fluorinated agent (i.e., PFPA) to ensure an efficient and simple preparation step. In this way, different aprotic solvents including butyl chloride, ethyl 
acetate, and hexane were tested for their extraction capabilities. Under our selected conditions, butyl chloride showed better results in terms of sensitivity (highest signalto-noise ratios) and selectivity. Additionally, the sonication time and the temperature applied during the extractionderivatization single step were optimized. Thus, thirty minutes of sonication at $60{ }^{\circ} \mathrm{C}$ represents the best compromise in our case. Although the use of butyl chloride resulted in poorer extraction recovery compared with water or methanol for DBS application (data not shown), this aprotic organic solvent enabled the simultaneous use of PFPA, thus combining derivatization and extraction in a single step.

\section{Fast GC-NICI-MS-MS}

In the past several years, the development of a high-throughput analytical method has become a laboratory standard. Numerous studies have been published regarding theoretical approaches to optimization of GC speed [46]. Depending on the resolution required, it is possible to trade resolution for time [47]. In this way, an attractive approach is to use a faster programming temperature, which enables use of a narrow-bore column (i.e., $0.25 \mathrm{~mm}$ ), offering better robustness compared to a microbore column when repeated injections of biological matrices are carried out [32]. In our study, application of a $70^{\circ} \mathrm{min}^{-1}$ gradient enabled rapid and good separation, because the total analysis time was $5 \mathrm{~min}$, and the full widths at half-maximum (FWHM) were about $0.6 \mathrm{~s}$ for each compound, which is in agreement with fast $\mathrm{GC}$ requirements [47].

NICI is a highly selective and sensitive ionization mode for compounds with a high electron affinity [32, 48]. Although any molecule is able to capture an electron, only those with a positive electro-affinity will be stable enough to be detected. Thus, the derivatization is an important step in increasing the electro-affinity of the molecule and improving sensitivity and selectivity. Moreover, the high pressure of NICI contributes to thermalize the formed ion owing to the multiple low-energy collisions. This aspect is interesting when tandem mass spectrometry is used, because precursor ions will have a lower internal energy compared with other ionization modes such as electronic impact. Figure 1 shows the product ion spectra obtained for the antidepressants, which present few fragment ions and consequently better sensitivity. This weak fragmentation is interesting for these compounds, which have a low molecular mass, although it provides at least two transitions required for toxicological analysis (i.e., quantitation and identification).

In this work, the use of PFPA as fluorinated agents with the NICI-MS-MS enables observation of a very intense signal for our compounds of interest, although only $10 \mu \mathrm{L}$ of blood was used without any preconcentration step, in contrast with the conventional procedure (see Fig. 2 and the section "Selectivity, $L O Q$, and $L O D$ ").
Validation

\section{Response function}

Response functions were determined by use of several regression models $[49,50]$. The best results were obtained for weighted linear regression with a weight factor of $1 / x^{2}$ for each compound.

\section{Trueness and precision}

The trueness and the precision of the method were determined with independent QC DBS samples at each concentration level. Hence, the trueness was determined by calculating the percentage difference between experimental and theoretical concentration values, indicating systematic error. Precision which indicates random errors, was assessed by computing the relative standard deviation for the repeatability $\left(\mathrm{R}_{\text {R.S.D. }}\right)$ and the between day variability, expressed as the intermediate precision ( $\left.\mathrm{IP}_{\mathrm{R} . \mathrm{S} \text {.D. }}\right)$ [49-51]. Repeatability represents the given precision under conditions of repeatability (the same operator, the same samples, the same reagents, etc.). The intermediate precision represents the precision resulting from repetitions performed in a laboratory on the same sample but under different conditions (here, different days and reagents). As presented in Table 2, relative bias, $\mathrm{R}_{\mathrm{R} \text {.S.D. }}$ and $\mathrm{IP}_{\text {R.S.D. values were below } 12 \% \text { in }}$ agreement with the SFSTP validation criteria.

\section{Linearity and accuracy profiles}

The linearity of an analytical method is its capacity to provide results directly proportional to the concentration of the sample within a certain concentration range [51]. Linearity was calculated by fitting the back-calculated concentrations of the QCs as a function of the introduced concentrations and by applying the linear regression model based on the leastsquares method [50]. With coefficients of determination $\left(r^{2}\right)$ above 0.9986 and slope values between 0.998 and 1.114, the method was linear for the four antidepressants.

Figure 3 illustrates the relative accuracy profiles of the four antidepressants. These profiles, built using total error (bias and precision), provide an estimation of the uncertainty measurement of the entire linearity range. A relative error of $30 \%$ was selected as the acceptance threshold where the expected proportion of measures $(95 \%)$ was within the acceptance limits. As depicted, all of the accuracy profiles are between $\pm 30 \%$, demonstrating that the method is suitable for performing clinical and toxicological analyses. For this purpose, other antidepressants such as fluvoxamine, maprotiline, and sertraline were tested with the described procedure and preliminary results were satisfactory in terms of sensitivity and selectivity (data not shown). However, the lack of 

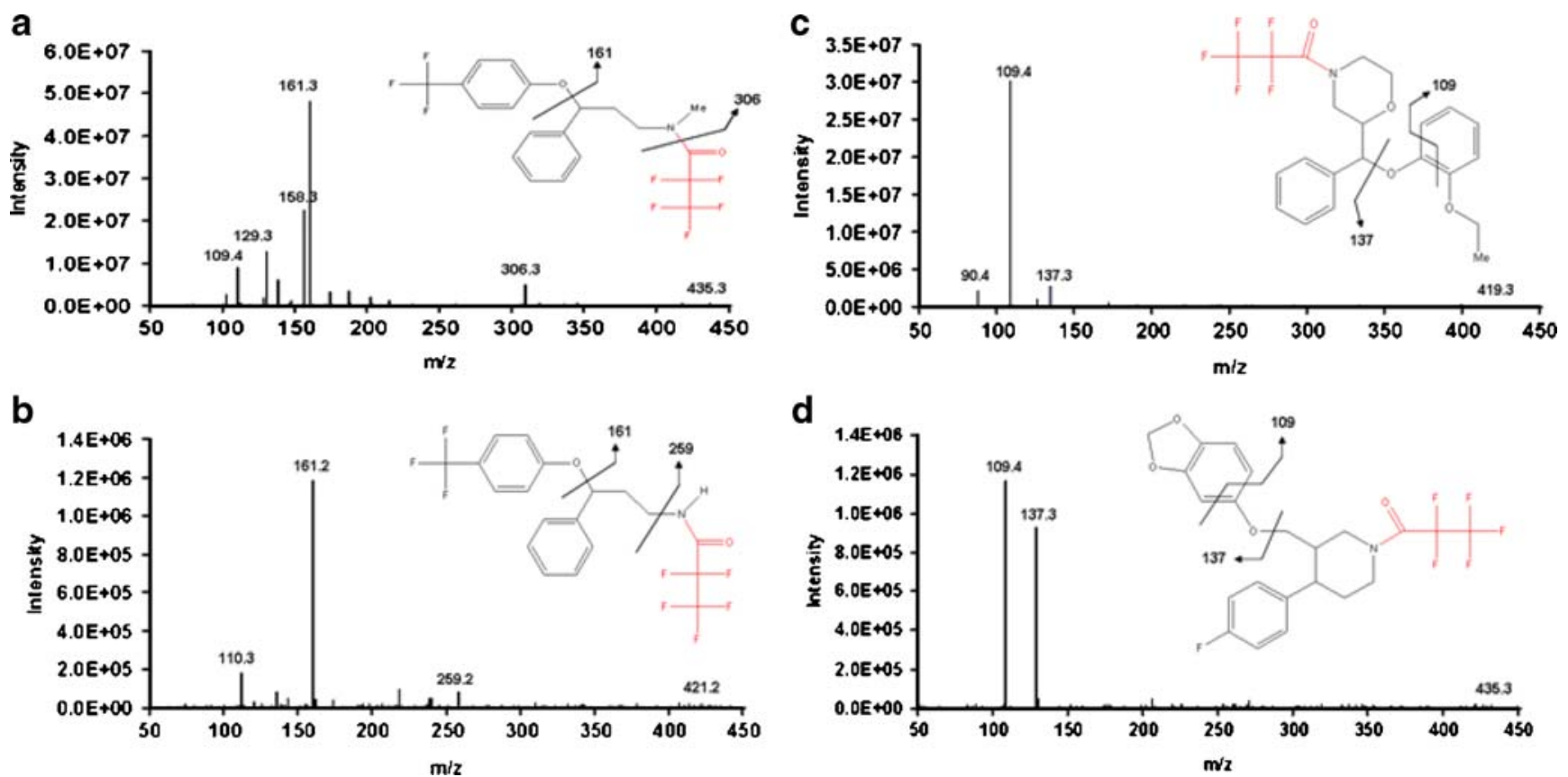

Fig. 1 Product-ion spectra of derivatives of the antidepressants after NICI ionization of: fluoxetine at a collision energy of $5 \mathrm{eV}$ (a), norfluoxetine at $15 \mathrm{eV}(\mathbf{b})$, reboxetine at $10 \mathrm{eV}(\mathbf{c})$, and paroxetine at $15 \mathrm{eV}(\mathbf{d})$. Fragmentation pathways are proposed for each compound

corresponding internal standard did not permit the inclusion of these compounds in this study.

\section{Selectivity, $L O D$, and $L O Q$}

In order to test the selectivity of the method, six different human blank DBSs were checked for interferences. Figure 2B shows a typical total ion current chromatogram of one blank DBS, demonstrating that no interfering peaks were present at the retention times of the compounds of interest. Carry-over was also investigated by injecting a blank solution (hexane) after injection of twice the highest calibration point. The results showed that no carry-over was observed with our procedure (lower than $0.01 \%$ ).

The sensitivity encountered was largely better than therapeutic requirements, which enabled safe quantification of the compounds with LOQ of $1 \mathrm{ng} \mathrm{mL} L^{-1}$ for fluoxetine and norfluoxetine and $20 \mathrm{ng} \mathrm{mL} L^{-1}$ for reboxetine and paroxetine (Figs. 2C-F), whereas the LODs were $20 \mathrm{pg} \mathrm{mL}^{-1}$ for each compound. LOQ was determined as the lowest QC with trueness and precision under $15 \%$, whereas LOD was estimated as three times the signal-to-noise ratio $(S / N)$.

\section{Recovery and matrix effects}

The results of the recovery and matrix effects investigations are summarized in Table 3. As depicted, recoveries obtained were acceptable for all compounds, even if extraction and derivatization were combined into a single step. Furthermore, no matrix effect was observed, which is in agreement with the use of NICI [34].

\section{Stability of DBS}

Numerous methods have shown that DBS offered high stability properties for many classes of compounds [15]. To
Fig. 2 Total ion current chromatograms of a blank filter paper (a) and human whole blood DBS (b), and selected reaction monitoring chromatograms of DBS containing norfluoxetine at $1 \mathrm{ng} \mathrm{mL} L^{-1}(\mathbf{c})$, fluoxetine at $1 \mathrm{ng} \mathrm{mL} \mathrm{m}^{-1}(\mathbf{d})$, reboxetine at $20 \mathrm{ng} \mathrm{mL}^{-1}(\mathbf{e})$, and paroxetine at $20 \mathrm{ng} \mathrm{mL}^{-1}$ (f)

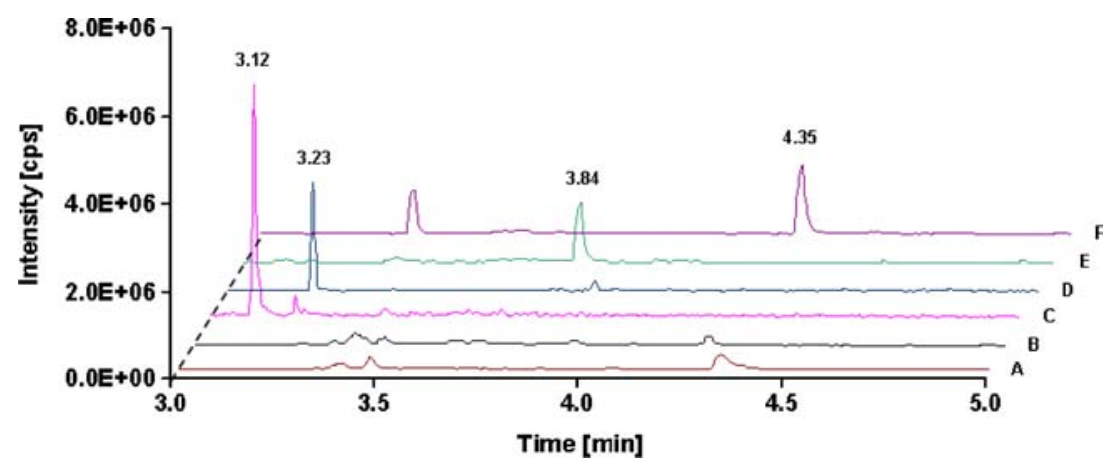


Table 2 Validation data

\begin{tabular}{|c|c|c|c|c|c|}
\hline Antidepressant & Nominal conc. $\left(\mathrm{ng} \mathrm{mL}{ }^{-1}\right.$ ) & Found conc. (ng mL $\mathrm{m}^{-1}$ ) & Relative bias (\%) & $\begin{array}{l}\text { Repeatability } \\
\text { (RSD, \%) }\end{array}$ & $\begin{array}{l}\text { Intermediate precision } \\
(\mathrm{RSD}, \%)\end{array}$ \\
\hline \multirow[t]{4}{*}{ Norfluoxetine } & 1 & 0.99 & -1.1 & 6.0 & 6.0 \\
\hline & 20 & 21.3 & 6.5 & 4.6 & 4.6 \\
\hline & 250 & 264 & 5.8 & 6.2 & 9.1 \\
\hline & 500 & 497 & -0.6 & 9.7 & 11.9 \\
\hline \multirow[t]{4}{*}{ Fluoxetine } & 1 & 0.99 & -1.3 & 5.5 & 8.2 \\
\hline & 20 & 19.9 & -0.5 & 8.5 & 8.5 \\
\hline & 250 & 272 & 8.7 & 6.2 & 6.2 \\
\hline & 500 & 550 & 10.1 & 2.5 & 7.6 \\
\hline \multirow[t]{4}{*}{ Reboxetine } & 20 & 21.6 & 7.7 & 7.6 & 10.1 \\
\hline & 40 & 43.6 & 9.1 & 5.1 & 8.3 \\
\hline & 250 & 258 & 3.1 & 8.3 & 8.3 \\
\hline & 500 & 552 & 10.3 & 6.7 & 8.4 \\
\hline \multirow[t]{4}{*}{ Paroxetine } & 20 & 21.4 & 7.0 & 6.5 & 9.8 \\
\hline & 40 & 38.5 & -3.8 & 5.8 & 5.8 \\
\hline & 250 & 261 & 4.4 & 4.8 & 6.4 \\
\hline & 500 & 556 & 11.2 & 5.1 & 7.4 \\
\hline
\end{tabular}
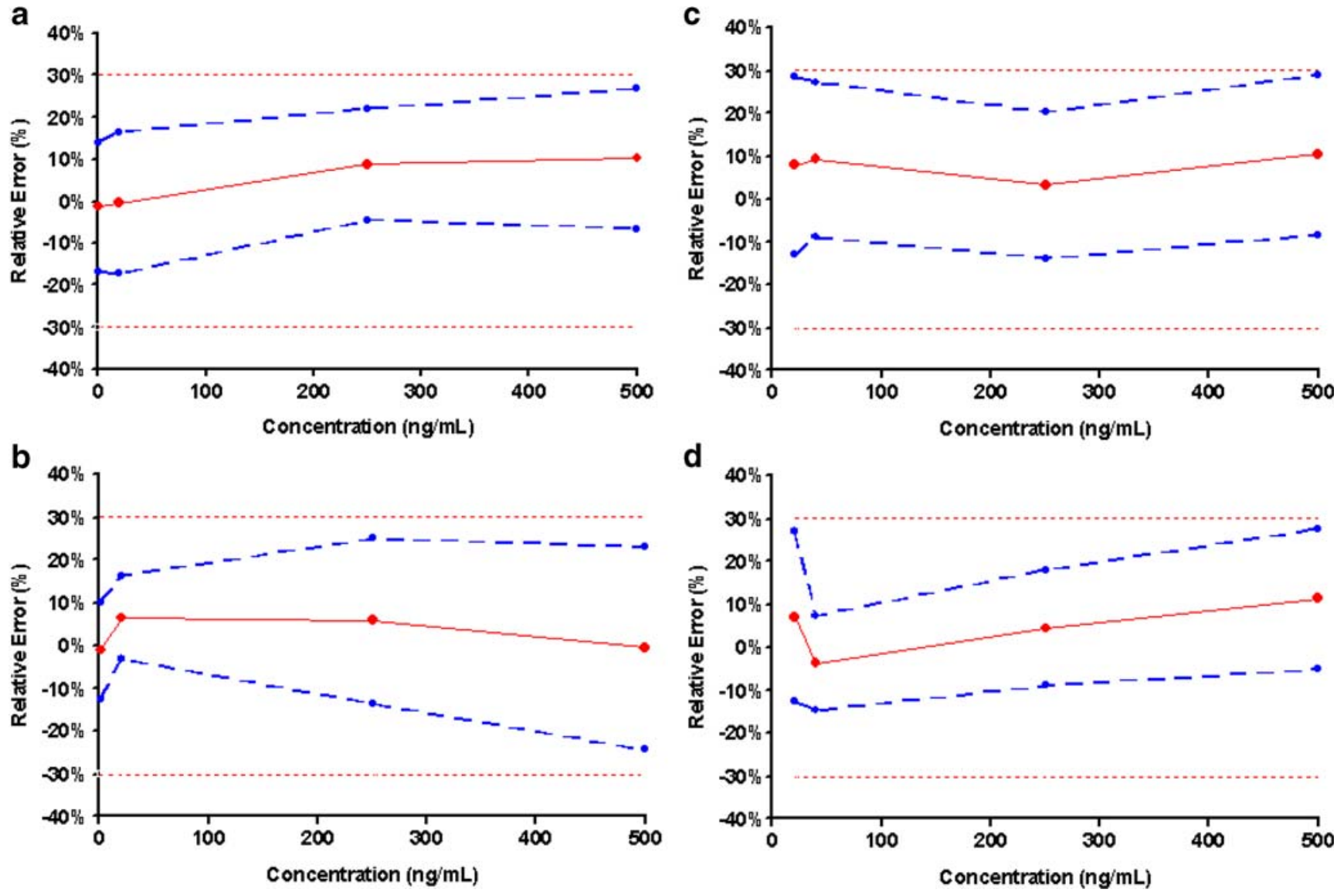

Fig. 3 Relative accuracy profiles of fluoxetine (a), norfluoxetine (b), reboxetine (c), and paroxetine (d) with $1 / x^{2}$ weight factor. The continuous line represents the trueness, the dashed lines are the upper

and lower accuracy limits in relative values, and the dotted lines are the upper and lower 30\% tolerance limits 
Table 3 Recovery and matrix effects for the four antidepressants at $250 \mathrm{ng} \mathrm{mL}^{-1}(n=3)$

\begin{tabular}{lll}
\hline Antidepressant & Matrix effect (\%) & Recovery/RSD (\%) \\
\hline Norfluoxetine & +1.7 & $81.6 / 3.8$ \\
Fluoxetine & +4.1 & $73.2 / 3.0$ \\
Reboxetine & -1.5 & $60.8 / 3.2$ \\
Paroxetine & -3.0 & $89.6 / 2.2$ \\
\hline
\end{tabular}
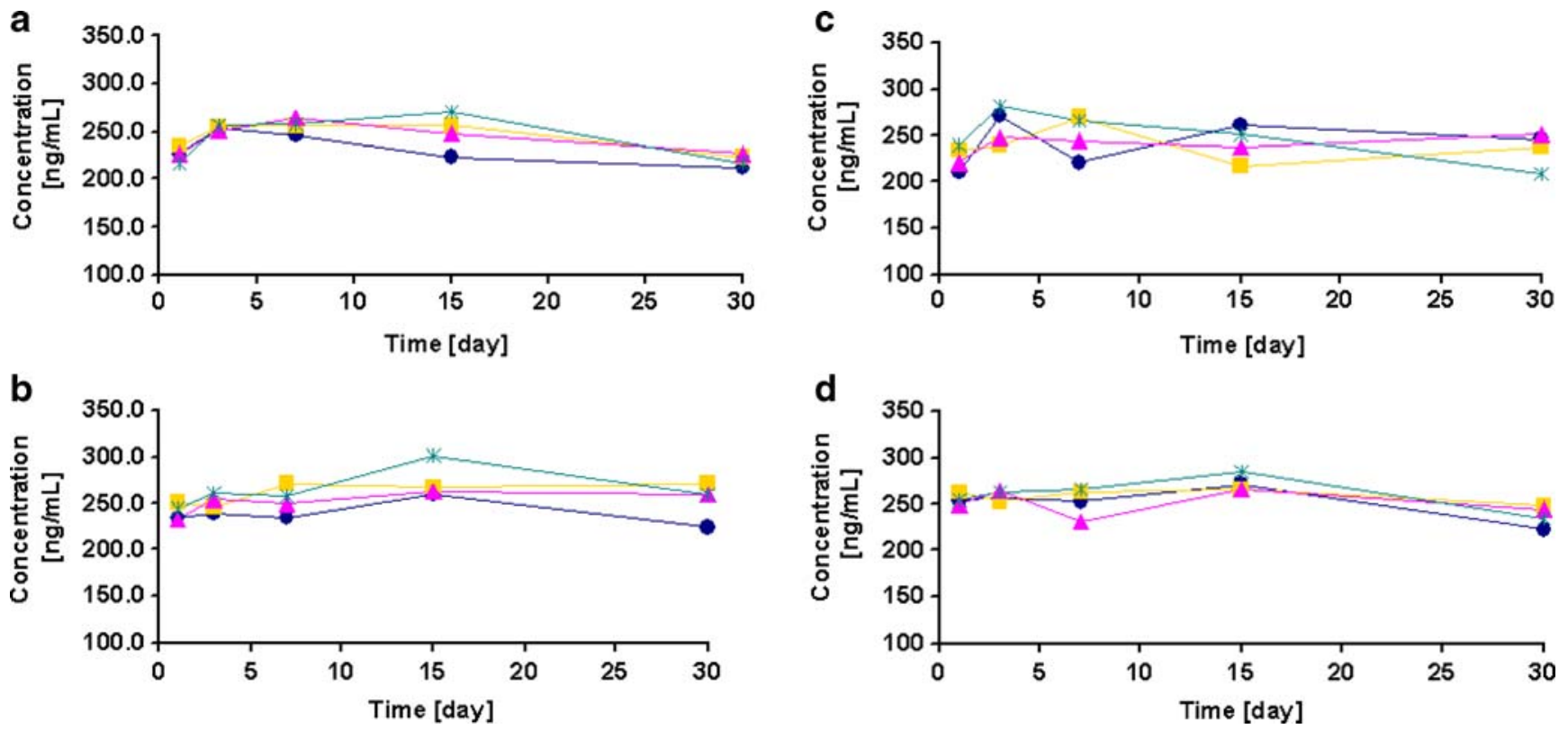

Fig. 4 Stability of fluoxetine (a), norfluoxetine (b), reboxetine (c), and paroxetine (d) spiked at $250 \mathrm{ng} \mathrm{mL}{ }^{-1}$ in DBS stored at $-20{ }^{\circ} \mathrm{C}($ crosses $)$, $4{ }^{\circ} \mathrm{C}$ (squares), $20{ }^{\circ} \mathrm{C}$ (triangles), and $40{ }^{\circ} \mathrm{C}$ (circles)

Fig. 5 Concentration vs. time profiles for fluoxetine (triangles) and norfluoxetine (squares) detected in DBS samples collected from a volunteer after oral administration of a single 40-mg dose of fluoxetine the best of our knowledge, antidepressant stability has never been investigated on filter paper.

Figure 4 shows good stability of fluoxetine, norfluoxetine, reboxetine, and paroxetine in dried blood spots over 30 days, as all tested DBS showed concentrations were between 85 and $115 \%$ of the initial concentration. Interestingly, no significant difference was observed between the four investigated temperatures, confirming that DBS can be stored at ambient temperature for a relatively long time period. With these 
considerations, the DBS sampling process provides a powerful tool in terms of storage and shipment of antidepressants because sampling can be performed in a non-hospital based environment, where refrigeration is problematic, or in other resource-limited settings.

After the extraction-derivatization step, autosampler stability of reconstituted samples was verified by re-injection of QCs after a waiting period of $12 \mathrm{~h}$ at ambient temperature. No statistical difference of analyte peak area was observed.

Pharmacokinetic investigation

Figure 5 shows representative concentration-time curves of fluoxetine and norfluoxetine after oral administration of fluoxetine. Because of to its high sensitivity, the outlined method enabled the quantification of fluoxetine and norfluoxetine up to 250 and $650 \mathrm{~h}$, respectively, from only $10 \mu \mathrm{L}$ blood samples.

The data processing estimated $C_{\max }$ at 49.5 and $13.0 \mathrm{ng} \mathrm{mL}{ }^{-1}, T_{\max }$ at 6.0 and $48.0 \mathrm{~h}, t_{1 / 2}$ at 40.5 and $106 \mathrm{~h}$, and $\mathrm{AUC}_{0-\infty}$ at 1906 and $3170 \mathrm{~h} \mathrm{ng} \mathrm{mL}{ }^{-1}$ for fluoxetine and norfluoxetine, respectively. The values obtained were close to those usually found in literature based on venous sampling $[52,53]$. Although the investigation was carried out on a single volunteer, the DBS sampling process seems to be as suitable for performing pharmacokinetic studies as classic venipuncture. However, further investigations are necessary to valuably compare results obtained from capillary blood and DBS, and from plasma and capillary specimens.

\section{Conclusion}

The objective of the work discussed in this article was to perform quantitative analyses of antidepressants from $10 \mu \mathrm{L}$ whole blood using the DBS sampling procedure. Because of its high sensitivity and selectivity, the use of NICI-MS-MS enabled detection of compounds of interest up to $20 \mathrm{pg} \mathrm{mL}^{-1}$ without preconcentration. Optimization of the extraction step by use of an appropriate solvent enabled combination of derivatization and extraction in a single step, reducing the sample-preparation time. Moreover, the use of fast GC conditions makes this assay suitable for high-throughput analysis. The method offered accurate quantification in terms of trueness and precision of the four antidepressants tested over their therapeutic concentration range.

DBS sampling coupled with GC-NICI-MS-MS was successfully applied to a pharmacokinetic investigation of fluoxetine and its active phase I metabolite on a healthy volunteer. As the stability of the antidepressants in DBS was shown to be unaffected by temperature, the pharmacokinetic samples were shipped by mail without a refrigeration device after collection by the volunteer himself at home. This simplified procedure is particularly advantageous when multiple samples are required.

Combining the numerous advantages of DBS sampling with a sensitive and efficient GC-NICI-MS-MS technique, this validated assay represents an interesting alternative for microanalysis to traditional methods used in therapeutic drug monitoring and pharmacokinetic studies.

Acknowledgments The authors would like to thank Dr Youssef Daali from the Division of Clinical Pharmacology and Toxicology, Geneva University Hospitals (Switzerland) for his help.

\section{References}

1. Kent JM (2000) Lancet 355:911-918

2. Wille SMR, Maudens KE, Van Peteghem CH, Lambert WEE (2005) J Chromatogr A 1098:19-29

3. Azaz-Lishits T, Hershko A, Ben-Chetrit E (2002) Pharmacopsychiatry 35:112-115

4. Adson DE, Erickson-Birkedahl S, Kotlyar M (2001) Ann Pharmacother 35:1375-1377

5. Kelly CA, Laing WJ, Strachan FE, Good AM, Bateman DN (2004) J Toxicol Clin Toxicol 42:67-71

6. Vaswani M, Linda FK, Ramesh S (2003) Prog Neuropsychopharmacol Biol Psychiatry 27:85-102

7. Mandrioli R, Forti GC, Raggi MA (2006) Curr Drug Metab 7:127133

8. ter Heine R, Rosing H, van Gorp ECM, Mulder JW, van der Steeg WA, Beijnen JH, Huitema ADR (2008) J Chromatogr B 867:205212

9. Damen CWN, Rosing H, Schellens JHM, Beijnen JH (2009) Anal Bioanal Chem 394:1171-1182

10. Boy RG, Henseler J, Mattern R, Skopp G (2008) Ther Drug Monit 30:733-739

11. Zytkovicz TH, Fitzgerlad EF, Marsden D, Larson CA, Shih VE, Johnson DM, Strauss AW, Comeau AM, Eaton RB, Grady GF (2001) Clin Chem 47:1945-1955

12. Mcdade TW, Williams S, Snodgrass JJ (2007) Demography 44:899925

13. Mei JV, Alexander JR, Adam BW, Hannon WH (2001) J Nutr 131:1631-1636

14. Cheung CY, van der Heijden J, Hoogtanders K, Christiaans M, Liu YL, Chan YH, Choi KS, van de Plas A, Shek CC, Chau KF, Li CS, van Hooff J, Stolk L (2008) Transpl Int 21:140-145

15. Edelbroek PM, van der Heijden J, Stlok LML (2009) Ther Drug Monit 31:327-336

16. Barfield M, Spooner N, Lad R, Parry S, Fowles S (2008) J Chromatogr B 870:32-37

17. Blessborn D, Römsing S, Annerberg A, Sundquist D, Björkman A, Lindegardh N, Bergqvist Y (2007) J Pharm Biomed Anal 45:282-287

18. Mwaba P, Cassol S, Pilon R, Chintu C, Janes M, Nunn A, Zumla A (2003) Lancet 362:1459-1460

19. Koal T, Burhenne H, Römling R, Svoboda M, Resch K, Kaever V (2005) Rapid Commun Mass Spectrom 19:2995-3001

20. Guidelines for the shipment of dried blood spot specimens (1995) Center for Diseases Control and Prevention, Atlanta, GA, USA; http:// www.cdc.gov/od/ohs/biosfty/driblood.htm. Accessed 20 December 2009

21. Lejeune D, Souletie I, Houzé S, Le Bricon T, Le bras J, Gourmel B, Houzé P (2007) J Pharm Biomed Anal 43:1106-1115 
22. Ntale M, Mahindi M, Ogwal-Okeng JW, Gustafsson LL, Beck O (2007) J Chromatogr B 859:137-140

23. la Marca G, Malvagia S, Filippi L, Fiorini P, Innocenti M, Luceri F, Pieraccini G, Moneti G, Francese S, Dani FR, Guerrini R (2008) J Pharm Biomed Anal 48:1392-1396

24. Coombes EJ, Gamlen TR, Batstone GF, Leigh PN (1984) Ann Clin Biochem 21(Pt 6):519-522

25. AbuRuz S, Millership J, McElnay J (2006) J Chromatogr B 832:202-207

26. Fujimoto T, Tsuda Y, Tawa R, Hirose S (1989) Clin Chem 35:867869

27. Allanson AL, Cotton MM, Tettey JNA, Boyter AC (2007) J Pharm Biomed Anal 44:963-969

28. van der Heijden J, de Beer Y, Hoogtanders K, Christiaans M, de Jong GJ, Neef C, Stolk L (2009) J Pharm Biomed Anal 50:664-670

29. Saint-Marcoux F, Sauvage FL, Marquet P (2007) Anal Bioanal Chem 388:1327-1349

30. Mauriala T, Chauret N, Oballa R, Nicoll-Griffith DA, Bateman KP (2005) Rapid Commun Mass Spectrom 19:1984-1992

31. Wille SMR, Van Hee P, Neels HM, Van Peteghem CH, Lambert WE (2007) J Chromatogr A 1176:236-245

32. Thomas A, Widmer C, Hopfgartner G, Staub C (2007) J Pharm Biomed Anal 45:495-503

33. Maurer HH (2002) Ther Drug Monit 24:247-254

34. Gunnar T, Ariniemi K, Lillsunde P (2006) J Mass Spectrom 41:741-754

35. Cirimele V, Kintz P, Ludes B (1997) J Chromatogr B 700:119-129

36. Kintz P, Tracqui A, Mangin P (1996) J Forensic Sci 41:851-854

37. Kuhlman JJ Jr, Magluilo J Jr, Cone E, Levine B (1996) J Anal Toxicol 20:229-235

38. Watson DG, Su Q, Midgley JM, Doyle E, Morton NS (1995) J Pharm Biomed Anal 13:27-32

39. Wilkins D, Haughey H, Cone E, Huestis M, Foltz R, Rollins D (1995) J Anal Toxicol 19:483-491
40. Boulanger B, Chiap P, Dewé W, Crommen J, Hubert P (2003) J Pharm Biomed Anal 32:753-765

41. Matuszewski BK, Constanzer ML, Chavez-Eng CM (2003) Anal Chem 75:3019-3030

42. Qu Y, Aluisio L, Lord B, Boggs J, Hoey K, Mazur C, Lovenberg T (2009) Pharmacol Biochem Behav 92:469-473

43. Vlase L, Imre S, Leucuta S (2005) Talanta 66:659-663

44. Hoogtanders K, van der Heijden J, Christiaans M, Edelbroek P, van Hooff JP, Stolk LML (2007) J Pharm Biomed Anal 44:658664

45. Kulik W, van Lenthe H, Stet FS, Houtkooper RH, Kemp H, Stone JE, Steward CG, Wanders RJ, Vaz FM (2008) Clin Chem 54:371378

46. Cramers CA, Leclercq PA (1999) J Chromatogr A 842:3-13

47. Mastovska K, Lehotay SJ (2003) J Chromatogr A 1000:153-180

48. Harrison AG (1986) Chemical ionization mass spectrometry. CRC Press, Boca Raton, Florida

49. Shah VP, Midha K, Dighe S, McGilveray LJ, Skelly JP, Yacobi A, Layloff T, Viswanathan CT, Cook CE, McDowall RD, Pittman KA, Spector S (1992) J Pharm Sci 81:309-312

50. Hubert P, Chiap P, Crommen J, Boulanger B, Chapuzet E, Mercier N, Bervoas-Martin S, Chevalier P, Grandjean D, Lagorce P, Lallier M, Laparra MC, Laurentie M, Nivet JC (1999) Anal Chim Acta 391:135-148

51. Hubert P, Nguyen-Huu JJ, Boulanger B, Chapuzet E, Chiap P, Cohen N, Compagnon NA, Dewé W, Feinberg M, Lallier M, Laurentie M, Mercier N, Muzard G, Nivet C, Valat L (2004) J Pharm Biomed Anal 36:579-586

52. Keller T, Cambon N, Genevray M, Crivelli F, Crivelli M, Dal BL, Mazzuchelli P, Ismaili S, Marzo A (2005) Arzneimittelforschung 55:491-497

53. Najib NM, Idkaidek N, Beshtawi M, Mohammed B, Admour I, Alam SM, Dham R, Qumaruzaman (2005) Biopharm Drug Dispos 26:243-247 